\title{
Updates on the Management of Epistaxis
}

\author{
Chin-Lung Kuo, MD, PhD ${ }^{12^{\star}}$ \\ 1 Department of Otolaryngology, Taoyuan Armed Forces General Hospital, Taoyuan, Taiwan \\ ${ }^{2}$ Institute of Brain Science, National Yang-Ming University school of Medicine, Taipei, Taiwan
}

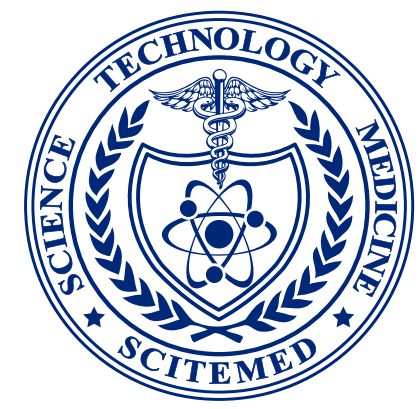

\begin{abstract}
Epistaxis (i.e., nosebleed) is a common otolaryngologic emergency; however, it is seldom life-threatening and most minor nosebleeds stop on their own or under primary care from medical staff. Nonetheless, cases of recurrent epistaxis should be checked by an otolaryngologist, and severe nosebleeds should be referred to the emergency department to avoid adverse consequences, including hypovolemic shock or death. This paper reviews current advances in our understanding of epistaxis as well as updated treatment algorithms to assist clinicians in optimizing outcomes.
\end{abstract}

\section{INTRODUCTION}

Epistaxis refers to hemorrhaging from the nose (i.e., nosebleed). This condition is among the most common otolaryngologic emergency, affecting roughly $60 \%$ of individuals [1], of whom 6-10\% require medical attention [2-6]. Most individuals experiencing epistaxis do not pursue medical help; however, if not dealt with in an appropriate manner, cases of extreme bleeding can lead to airway obstruction, aspiration, asphyxiation, hypovolemic shock, or even death [7-9]. Recent advances in endoscopy have facilitated nasal examinations; however, the effective management of this condition depends on an awareness of the probable sources of epistaxis and a comprehensive understanding of the nasal structure. This paper presents a review of the literature on epistaxis including recent advances in its treatment. This article also provides stepwise algorithms to guide clinicians through the decision process underlying the management of epistaxis.

\section{EPIDEMIOLOGY}

Epistaxis occurs in up to $60 \%$ of the general population [6]. The incidence of epistaxis presents a bimodal distribution, with most cases occurring in individuals below the age of 10 and above the age of 70 [6,10-12]. The average age of patients hospitalized for nosebleed is 70 years old [13]. Elderly individuals account for $40 \%$ of the cases requiring medical intervention, due primarily to the fact that bleeding events among the elderly can have severe consequences. Children tend to present with uncomplicated nosebleeds in the anterior region, which seldom require surgical intervention [14]. Despite the low prevalence of epistaxis among children below the age of 2, all such cases should be carefully examined for signs of trauma, the presence of an external object, or systemic illness [15]. Males are slightly more likely than are females to experience epistaxis $[12,16]$, due perhaps to the protective effects of estrogen $[11,17-19]$. Thus, there is a predominance of males among hospitalized patients below the age of 49 and a more equal sex distribution above this point.

\section{ANATOMY}

The primary functions of the nose include warming and humidifying inhaled air. This requires copious quantities of blood from external and internal carotid arteries (Figure 1). The external carotid artery serves as the major contributor and provides arterial flow primarily via the maxillary artery and secondarily via the facial artery. The maxillary artery splits into several branches, including the sphenopalatine artery and descending palatine artery. The sphenopalatine artery supplies the mucosa in most of the nasal septum and turbinates. The descending palatine artery has two or three branches, including the greater palatine artery, which takes a circuitous course passing inferiorly through the greater palatine canal and foramen to supply the nasal septum and floor of the nose. The facial artery divides into various branches, including the angular artery, lateral nasal artery, and superior labial artery, which supplies the septum and nasal alae [7]. The internal carotid artery supplies the region above the middle turbinate broadly via the anterior and posterior ethmoid arteries.

\section{TYPES OF EPISTAXIS}

Nosebleeds are categorized as primary or secondary. Primary nosebleeds are idiopathic and spontaneous, whereas secondary events have definite causes, such as trauma or the use of anticoagulants [20]. Despite the complexity of the circulatory system in the nose, on the other hand, nosebleeds can also be categorized simply as anterior or posterior, depending upon the source of bleeding. Most cases of epistaxis (90\% to $95 \%$ ) occur at an anastomosis referred to as Kiesselbach's plexus or Little's area in the inferior region of the anterior septum [11,21-25]. This area is saturated with branches of the superior labial artery, anterior and posterior ethmoid arteries, sphenopalatine artery, and greater palatine artery. These arteries are supplied by base branches of the internal and external carotid arteries [26]. A relatively small number of cases of epistaxis ( 5 to $10 \%$ of the total) are associated with arteries beneath the posterior end of the inferior turbinate, which forms Woodruff's plexus $[21,24,27]$.

\section{ETIOLOGY}

Epistaxis is a multifactorial entity. The etiology of nosebleeds can be categorized according to the cause as local, systemic, environmental, or drug-related. The local origins of epistaxis include trauma, intranasal neoplasia, inflammatory disease, and septal abnormality. A rich vascular network renders the nose susceptible to epistaxis. This is exacerbated by the fact that blood vessels within the nasal mucosa are outwardly situated, leaving them exposed to damage. Most of the cases encountered by clinicians involve some sort of trauma or irritation to the mucosa and/or associated blood vessels [28,29]. One common example is injury resulting from the insertion of a finger (nose picking) [30]. Kiesselbach's plexus is completely exposed just within the cavity of the nose. Nosebleeds due to blunt trauma are typically from an anterior source. 


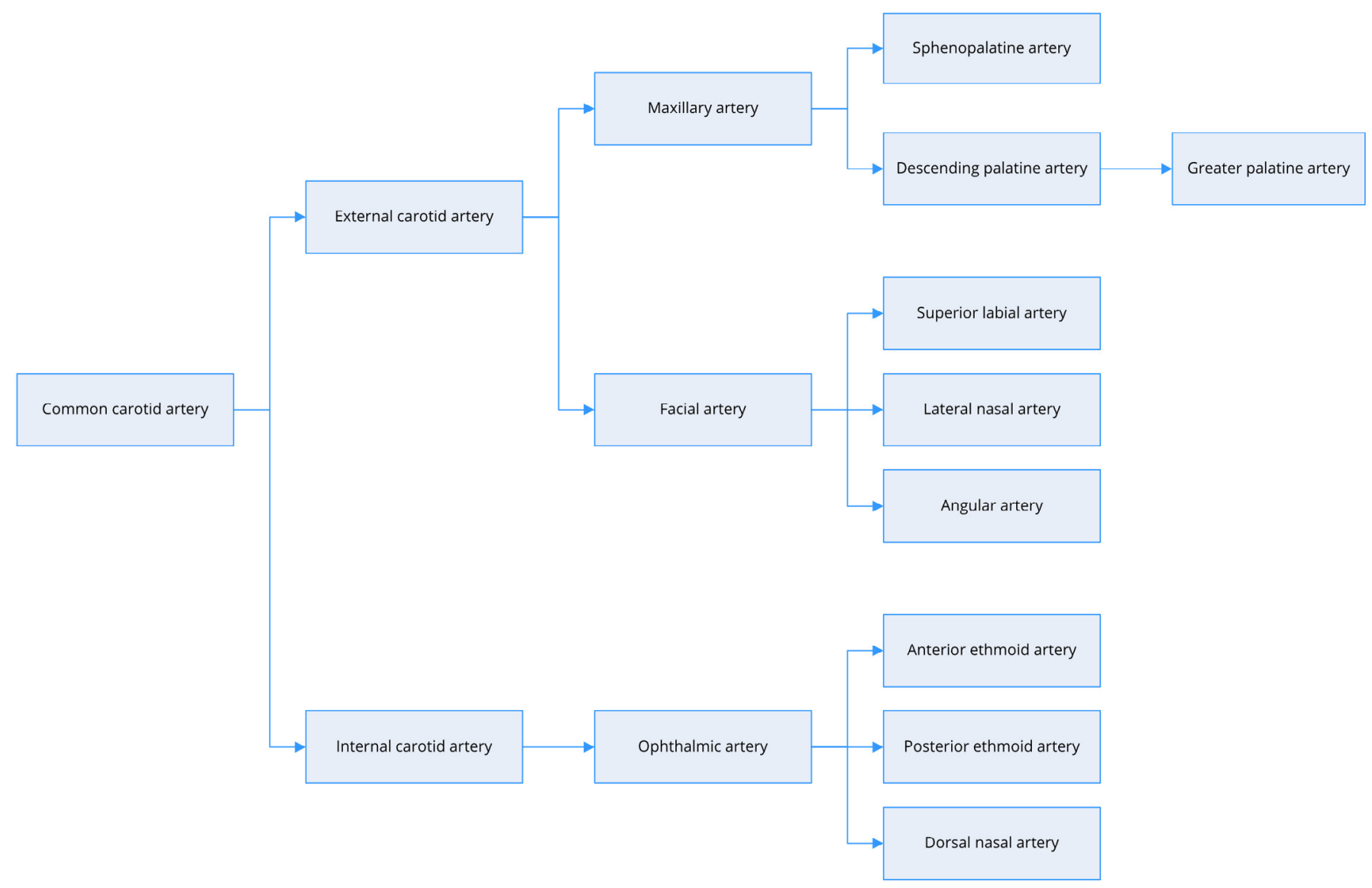

Figure 1. Arterial supply of the nasal cavity.

The introduction of a foreign object into the nose can cause profuse bleeding. In cases where the item has remained in that position for more than 24 hours, bleeding may be accompanied by pus-filled nasal discharge [31]. Nasotracheal intubation, nasogastric tube insertion, and the chronic use of nasal cannula are some of the most common causes of epistaxis among hospitalized patients. Fiberoptic guidance during nasotracheal intubation has been shown to reduce the incidence and severity of epistaxis, compared with conventional (unguided) insertion [32]. Recurrent epistaxis can be caused by sinonasal tumors, including squamous cell carcinoma, adenoid cystic carcinoma, melanoma, inverted papilloma, or other rare tumors [25,33]. It is notable that nasopharyngeal cancers are far more common among southeast Asians than among Caucasians [34]. The possibility of nasopharyngeal cancer needs to be excluded in southeast Asians with nosebleeds, in particular if specific symptoms and signs are concurrently observed, such as unilateral aural fullness and neck masses. When dealing with teenagers suffering from nosebleeds, it is imperative to consider juvenile nasopharyngeal angiofibroma, a benign but aggressive and expansile tumor that can invade adjacent structures resulting in extensive bleeding [35]. Cases of neoplasia are rare; however, it is important that clinicians conduct a rigorous examination to conclusively exclude this possibility.

Systemic causes of epistaxis include hypertension, cirrhosis, alcoholism, aberrations in clotting ability, inherited bleeding diatheses, and vascular/ cardiovascular diseases $[20,36,37]$. Despite the fact that hypertension is not a direct cause of epistaxis, it has been linked to cases of severe or refractory epistaxis $[15,36,38]$. Some researchers have surmised that hypertension as- sociated with an underlying vasculopathy that includes atherosclerosis may be a risk factor for epistaxis [39]; however, there is little evidence to support this assertion [40]. Furthermore, elevated arterial blood pressure at the onset of epistaxis may also be associated with stress and/or white coat syndrome [41]. Alcohol has been linked to an elevated risk of epistaxis [42]. Alcohol consumption reduces platelet aggregation, which can prolong the duration of bleeding. Hemodynamic changes may also be associated with some cases of epistaxis. Epistaxis is the most common manifestation in patients with hereditary hemorrhagic telangiectasia ( $\mathrm{HHT}$, also called Osler-Weber-Rendu syndrome), occurring in $90 \%$ to $95 \%$ of patients [43]. HHT is an autosomal dominant vascular disorder, which has been somewhat under reported [44]. Several patients with HHT have been found to be resistant to treatment for epistaxis, including oral estrogen, topical estriol plus argon plasma coagulation, oral tamoxifen, oral tranexamic acid, submucosal bevacizumab, topical bevacizumab, and sclerotherapy [43,45-50]. Intravenous bevacizumab [51] and thalidomide $[52,53]$ have been reported as effective and safe in reducing the incidence of epistaxis in HHT patients; however, further research is required to validate the benefits in terms of quality of life. Many patients with other bleeding ailments suffer from recurrent episodes of epistaxis [45]. It is essential to consider a bleeding diathesis when treating patients with recurrent spontaneous epistaxis [11,54].

Environmental factors also play an important role in the onset of epistaxis. There is a general increase in epistaxis in the winter months, due to lower temperatures and drier air $[11,16,36,55]$. Dry air tends to irritate the mucosa, leaving it susceptible to bleeding under even slight aggravation. Irritation from 
nasal infection or allergic rhinitis can also make the nasal mucosa friable, following the inflammation of nasal turbinates [13,42,56-61]. Epistaxis has been associated with the topical use of nasal steroids; however, the incidence of epistaxis among patients taking these drugs is only slightly above the incidence of those taking a placebo, and the symptoms are usually minor and self-limiting [62-66]. Manfredini et al. linked the incidence of epistaxis to cardiac rhythms. They found that the time of epistaxis occurrence presents a biphasic circadian pattern, with a primary peak in the morning, a smaller secondary peak in the evening, and a nocturnal nadir [67]. The authors commented that this biphasic pattern closely resembles the circadian rhythm of blood pressure, suggesting that blood pressure may be associated with epistaxis.

A number of drugs such as warfarin, dipyridamole, rivaroxaban, and nonsteroidal anti-inflammatory drugs (NSAIDs) can affect blood coagulation $[1,29,40,68]$. NSAIDs, including aspirin and ibuprofen, are the most common drugs that may interfere with coagulation [45]; however, researchers have yet to establish a definitive causal association between the use of NSAIDs and epistaxis [69-71]. It has been estimated that $24 \%$ to $33 \%$ of patients admitted for nosebleeds are taking anticoagulants or antiplatelet medications [2]. Vitamin $\mathrm{K}$ antagonists, such as phenprocoumon, have also been shown to contribute to recurrent epistaxis $[68,72]$. It has been reported that specific serotonin reuptake inhibitors and antibiotics can induce epistaxis; however, most of those bleeding episodes are mild and easily reversed [1]. Overall, it is important that clinicians refer to the medication history of patients with epistaxis and consider alternative causes.

Patients undergoing treatment with anticoagulants face an elevated risk of nosebleeds; however, there are as yet no clear guidelines regarding the means by which epistaxis patients should be treated in cases of an elevated international normalized ratio (INR) of 5 or more [11]. There is also a degree of controversy regarding whether patients with thromboembolic risks presenting with a minor nosebleed or bleeding from an inaccessible site should be treated using local measures or surgical interventions. Further high-quality research will be required to resolve this issue $[73,74]$. At present, clinicians base their selection of treatment methods on the site and extent of bleeding, history of bleeding, the perceived likelihood of progression to more severe bleeding, comorbidities including hypertension and renal insufficiency, INR level, and the likelihood that INR has been supratherapeutic over the previous few measurements [75]. Treatment options include ceasing warfarin treatment, ceasing warfarin with vitamin $\mathrm{K}$, or initiating aggressive anticoagulation reversal for patients presenting with pronounced bleeding [73]. As long as hemostasis can be achieved, patients with mild nasal bleeding can safely continue with their warfarin regimen, albeit with suitable adjustments [28]

\section{MANAGEMENT OF EPISTAXIS}

\section{Evaluation of Epistaxis}

Figure 2 presents a flow diagram detailing the evaluation and management of patients with epistaxis. Before examining patients with epistaxis, practitioners must ensure that the patient has a patent airway and cardiovascular stability. In cases of extensive bleeding and/or low blood pressure, it is important to transport the patients to the emergency department as soon as possible to avoid subsequent consequences. Clinicians in the emergency department should collect data related to blood type and cross-matching for possible blood transfusions [76,77].

After confirming hemodynamic stability, clinicians should collect a focused history to identify the factors that could contribute to epistaxis. Clinicians should obtain an account of the acute episodes and previous incidents (if any), including the extent, seriousness, frequency, and laterality of nosebleeds, as well as the methods used to control them. In cases of severe hemorrhaging or refractory epistaxis, it is important to consider conditions that predispose the patient to bleeding or other related injuries, including coagulation disorders, medications, and alcohol consumption. It is also crucial that clinicians inquire about hematemesis and the occurrence of black, tarry stools [45]. Patients undergoing treatment with anticoagulants should be evaluated to identify potential hemostatic disorders. Routine clotting screening is not required for patients who do not present with relevant risk factors [78,79].

The initial evaluation is meant to eliminate factors that could predispose the patient to epistaxis and identify the source of bleeding. Epistaxis can be classified as anterior or posterior according to the source of bleeding, and it is crucial to differentiate between the two. Anterior nosebleeds are the most common and are usually self-limited. Posterior epistaxis generally involves more profuse bleeding and cannot always be managed in a primary care setting [11]. Slight bleeding is generally indicative of an anterior source; however, a large volume of blood does not necessarily indicate a posterior source. Bleeding from both the nostrils is a clear indication of a posterior source. Bilateral epistaxis can occur in patients with a septal defect or bilateral nasal lesions.

\section{Initial Management of Epistaxis}

Initial management includes the application of pressure to areas of bleeding using cotton or gauze saturated in a topical decongestant $[80,81]$. In cases where a clinician is unable to determine the source of the bleeding, nasal packing should be applied in both nasal cavities using vasoconstrictor-soaked pledgets to hasten hemostasis. Vasoconstrictors, such as oxymetazoline, phenylephrine, or lidocaine, can reduce topical bleeding through vasoconstriction without the risk of elevating systemic blood pressure [80,82]. If this proves insufficient to halt bleeding, then the source is most likely posterior, and posterior packing may be required. Tilting the head forward helps to prevent the pooling of blood in the posterior pharynx and thereby may prevent nausea and airway obstruction.

The severity of epistaxis can range from light nosebleeds to potentially fatal bleeding. Minor events are easily managed in a clinical environment; however, major events often require hospital admission and even surgical intervention. In the event that the patient does not respond to initial treatment, efforts must be made to find the cause of the bleeding $[6,68,83]$. Children must be examined closely for a foreign body or nasal mass to ensure that epistaxis is benign [84]. Bleeding disorders should also be clinically excluded for patients with recurrent epistaxis.

\section{Treating Anterior Epistaxis}

Compression is the primary treatment mode for minor anterior epistaxis. This involves having the patient bend forward at the waist while sitting up to avoid swallowing blood. The clinician then applies pressure by grasping the alae distally and pinching them tightly against the septum without releasing the pressure for 5 to 10 minutes. If the initial treatment fails to stop the bleeding, a plug of cotton wool or a pledget can be inserted into the nasal cavity. Blood clots accumulated in the pharynx should be gently removed by suction, and a cold compress can be applied to the bridge of the nose before referring the patient to a specialist.

Patients lacking hemodynamic stability should be immediately referred to the emergency room for stabilization. Stadler et al. reported that an emergency consultation for epistaxis may be an unfavourable predictor of mortality [85]. Patients who are expected to maintain hemodynamic stability should be referred to an otolaryngologist for a more comprehensive medical evaluation and management [11]. The adoption of nasal endoscopes in the field of otorhinolaryngology has shifted the paradigm by which epistaxis is treated and has greatly improved outcomes. Endoscopes make it far easier to identify the point of bleeding with a high degree of accuracy [86]. It has been reported that without endoscopic assistance, clinicians fail to identify the point of bleeding in up to $50 \%$ of cases involving severe epistaxis [86].

Topical vasoconstrictors, such as oxymetazoline, phenylephrine, and lidocaine, have proven highly effective in the treatment of epistaxis [80,82]. Otolaryngologists spray a vasoconstrictor into the bleeding nostril and then insert a vasoconstrictor-soaked pledget into both nasal cavities and compress them tightly for 5 to 10 minutes before slowly removing the pledgets [80]. During nasal packing, it is important that the clinician inspect the oropharynx for signs of continuing bleeding. 


\section{REVIEW}

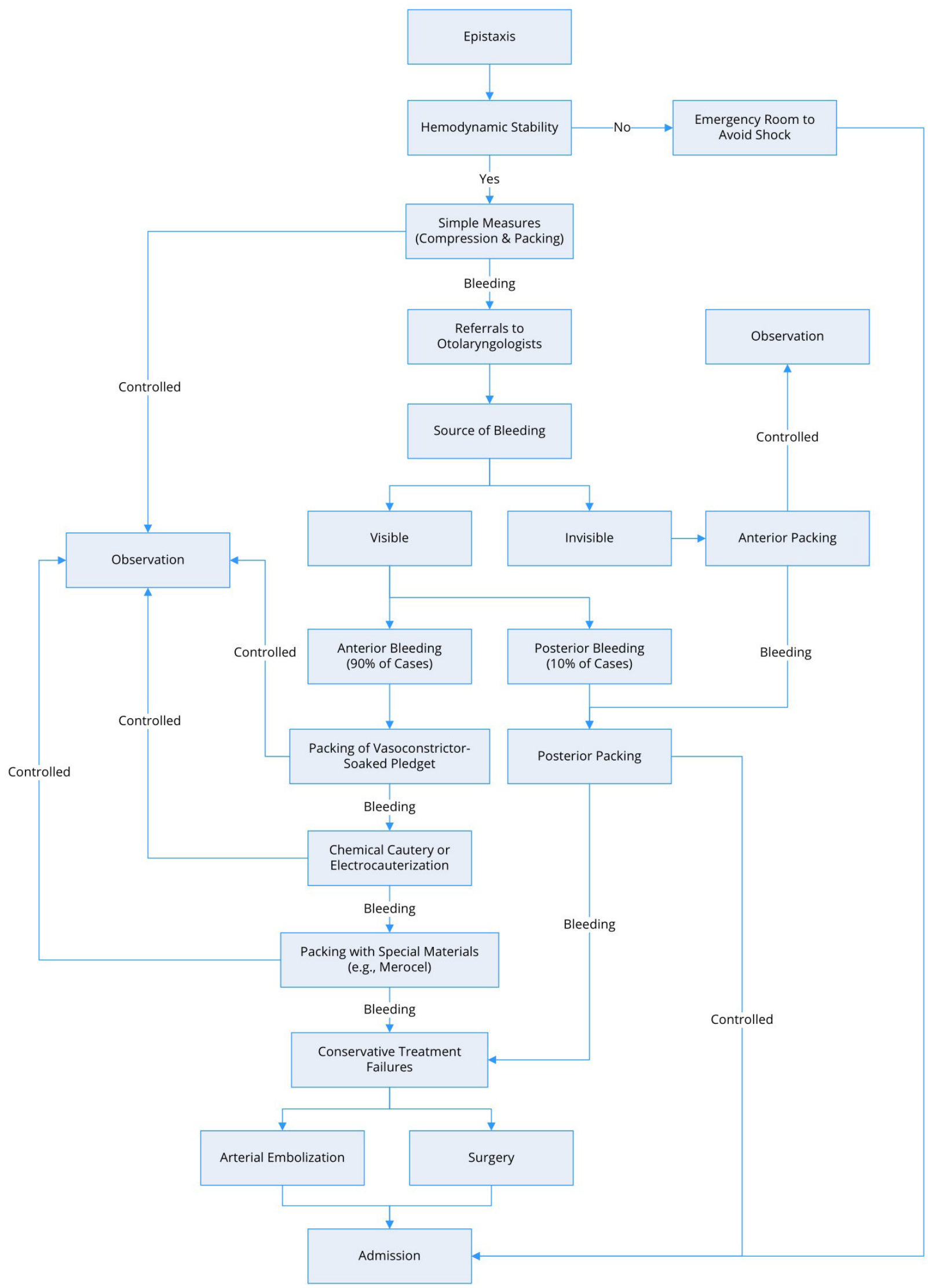

Figure 2. Flow diagram for the management of epistaxis. 
In cases where direct pressure using vasoconstrictor-soaked pledgets is unsuccessful, chemical cautery can be attempted. This involves the application of a silver nitrate stick directly to the bleeding point for 10 to 20 seconds. Topical silver nitrate interacts chemically with the lining of the nasal mucosal, causing it to become inflamed. This leads to the excretion of fibrinous exudate, which coagulates on the surface to form a pseudomembrane that stops the bleeding [87]. Electrocauterization is also effective in dealing with persistent epistaxis of the anterior septum. A metallic hoop warmed by an electric circuit is placed around the bleeding artery, thereby enabling the application of heat to the affected area via radiation (i.e., without coming into direct contact). It is notable that the overuse of cauterization or the application of these techniques to both sides of the nasal septum can lead to septal perforation or other mucosal trauma, which may worsen the bleeding.

A failure to identify the bleeding point or stop the bleeding via cauterization is an indication that pressure should be applied directly at the site of epistaxis using special packing materials lubricated with antibiotic ointment. Several packing materials have been developed specifically for the treatment of epistaxis to overcome the difficulties involved in inserting conventional ribbon gauze (e.g., Vaseline or bismuth-iodoform paraffin paste impregnated packs). Two common pre-prepared packs on the market include non-absorbable Merocel (Medtronic Inc., Minneapolis, MN, USA) and absorbable Nasopore (Polyganics, Groningen, the Netherlands). In randomized, controlled trials, these materials were shown to stop the bleeding in approximately 60 to $90 \%$ of refractory cases [88-91].

Merocel is a sponge of hydroxylated polyvinyl acetate, which has been compressed through dehydration. Rehydration through the injection of normal saline causes it to increase in size within the nasal cavity, thereby compressing the bleeding point [92]. It also allows localized clotting factors to reach the concentration levels required for coagulation [87]. The downside of non-absorbable packing is the need to remove it, which can cause the patient considerable pain and discomfort. Nasopore is dissolvable, bioresorbable foam, which expands through the absorption of water to support the surrounding tissue and apply pressure to bleeding vessels in the nasal cavity. Nasopore can be suctioned from the nasal cavity after it begins to dissolve, usually within a few days of insertion [92]. Note that nasal packing material should always be inserted backwards along the roof of the mouth, instead of upwards. Incorrect insertion of these materials can exacerbate mucosal damage and worsen the bleeding. In the event that nasal bleeding continues after initial packing, additional packing on the opposite side of the nasal cavity is required.

\section{Treating Posterior Epistaxis}

Cases of posterior epistaxis are far less common and are generally referred to otolaryngologists for further management [26]. Difficulties in imaging and accessing the source of bleeding can greatly hinder treatment efforts. Several packing strategies have been devised for posterior epistaxis. In some cases, packing is meant only to stem the bleeding until a surgical solution can be implemented. The conventional approach involves the insertion of rolled gauze through the choana, which is then held in place in the oropharynx using silk stitches $[45,93]$. A number of companies have developed "posterior packs", most of which involve the inflation of balloon catheters in the nasopharyngeal space to halt epistaxis. One alternative to posterior nasal tamponade is the insertion of a 10 to 14 French Foley catheter into the nasal passageway until it is visible in the oropharynx. The balloon is then filled with 10 to $15 \mathrm{~mL}$ of sterile water, whereupon the Foley catheter is retracted anteriorly until it is lodged against the posterior choana within the nasopharynx $[11,45]$. The catheter can be secured using a clamp before inserting an anterior pack.

Hot water irrigation is another approach to controlling posterior epistaxis [94-98]. A modified epistaxis-balloon-catheter is introduced into the bleeding nasal cavity to obstruct the choana. Continuous irrigation using $500 \mathrm{~mL}$ of hot water $\left(50^{\circ} \mathrm{C}\right)$ is then applied for 3 minutes. This treatment is meant to decrease local blood flow by inducing mucosal edema. It is also meant to assist in clearing blood clots from the nasal cavity.
After packing, it is important to examine the oropharynx to determine whether posterior nasal bleeding has ceased. If the nasal packing proves effective, then it should be kept in place for 24 to 72 hours to enable time for healing prior to removal $[7,25,45,99]$. Maintaining nasal packing for longer than 72 hours increases the risk of complications, such as necrosis, toxic shock syndrome (fever, hypotension, desquamation, and mucosal hyperemia), sinus or nasolacrimal infections, and dislodgment [11].

\section{Managing Conservative Treatment Failures}

In cases where bleeding continues after packing, the patient should be immediately transferred to the emergency department for further management via arterial embolization or surgical intervention. For more than 30 years, embolization has proven to be a highly effective alternative to surgical ligation in the treatment of posterior epistaxis with success rates of approximately $90 \%$ [93]. The reported rate of severe complications, including stroke or blindness, ranges from 2 to $4 \%[93,100]$. Before conducting an arteriogram, it is important to perform an otolaryngologic examination for the localization and/or lateralization of bleeding points. In the event that embolization fails to stop the bleeding, then surgical intervention is required.

When surgical intervention is deemed the only remaining option, the arteries to be targeted must first be identified based on physical examinations, endoscopic results, and the medical history of the patient. The conventional approach to the surgical ligation of ethmoidal vessels involves Lynch incisions [101]. Bipolar electrocoagulation is applied to clip or coagulate vessels after raising the periosteum off of the lacrimal crest and posteriorly into the orbit. Advances in endoscopy have also led to the development of endoscopic ligation techniques [102-104]. It is very likely that endoscopic artery ligation is a better treatment option for posterior epistaxis, due to its effectiveness and the fact that it is far less costly than is endovascular embolization [12]. Note that there may be an overlay between the right and left arterial systems, which can result in continuous nosebleeds despite unilateral arterial ligation.

\section{COMPLICATIONS}

Cauterization brings with it the risk of septal perforation, whereas packing can induce compression necrosis. The distress felt by patients undergoing these procedures can be alleviated using oral painkillers. Any packing method can result in a walled-off cavity in the sinuses, which greatly increases the risk of infection, toxic shock syndrome, or sinusitis [61]. Otolaryngologists therefore recommend the administration of prophylactic antibiotics with staphylococcal coverage, including amoxicillin-clavulanate or a second-generation cephalosporin [91,104-110].

There is, however, still some debate regarding the prescribing of prophylactic antibiotics for patients with nasal packing to prevent secondary bacterial sinonasal infection or toxic shock syndrome $[11,111]$. In practice, prophylactic antibiotics should be administered only to those facing a higher risk of infection, such as those who are immunosuppressed, have diabetes, or are of advanced age [11].

The dislodgement of posterior packing due to erroneous positioning can intensify vagal tone, resulting in bradycardia, hypotension, hypoventilation, or aspiration. It is therefore recommended that patients who undergo posterior packing be hospitalized and kept under observation [8,112]. Hospitalization may also be required for patients who have serious comorbidities, related symptoms, and/or intractable anterior nasal bleeding

\section{DISCHARGE INSTRUCTIONS}

All patients who experience recurring epistaxis should be given rudimentary training in first-aid to deal with recurrences. They must first learn to apply pressure accurately in the cartilaginous region of the nose (rather than the nasal bridge) for at least 5 to 10 minutes. During compression, the patient should 
be sitting up and bent forward at the waist to minimize the risk of aspiration or the swallowing of blood into the oropharynx and stomach. The swallowing of excess quantities of blood can trigger a gag reflex and irritate the stomach that results in vomiting, which can exacerbate bleeding. Patients should refrain from hot foods, vigorous activities, and nose picking after treatment. It is also important to avoid nose blowing for 7 to 10 days after treatment [113].

Nasal saline washes, water-soluble creams, antiseptic creams, and/or petroleum jelly can help to keep the mucosa moist and assist in healing [112]. Clinical experience has shown that the application of generous quantities of petroleum jelly to the nostrils can prevent mucosal drying, which acts as a cost-effective solution for anterior nosebleeds. Researchers have demonstrated the efficacy of antiseptic creams for the treatment of persistent epistaxis in children as well as in adults [114]. Humidifiers are an effective preventive measure in dry environments, particularly during sleep. Parents should ensure that their children's fingernails are clipped in order to reduce the damage from nose picking.

\section{CONCLUSION}

Numerous advances have been made in the management of epistaxis. Depending upon the suspected underlying cause of epistaxis and the equipment available at the primary care facility, practitioners may choose between conventional methods (e.g., nasal packing) and more sophisticated methods (e.g., electric cauterization and endoscopic devices). This article provides a useful flow diagram for the management of epistaxis to assist clinicians in clinical practice. There remains a dearth of high-quality research results by which to better formulate treatment algorithms aimed at optimizing outcomes.

\section{ARTICLE INFORMATION}

*Correspondence: Chin-Lung Kuo, MD, PhD, Department of Otolaryngology-Head and Neck Surgery, Taoyuan Armed Forces General Hospital, Taoyuan, Taiwan. E-mail: drkuochinlung@gmail.com

Received: Sep. 18, 2018; Accepted: Oct. 31, 2018; Published: Mar. 12, 2019

DOI: $10.24983 /$ scitemed.cmt.2019.00106

Ethics Approval and Consent to Participate: The study is in accordance with the ethical standards of the 1964 Helsinki declaration and its later amendments or comparable ethical standards.

Funding: This study was sponsored by grants from Medical Affairs Bureau Ministry of National Defense (MAB-107-099) and Taoyuan Armed Forces General Hospital (AFTYGH-10734 and AFTYGH-10830).

Conflict of Interest: The authors report no financial or other conflict of interest relevan to this article, which is the intellectual property of the authors.

Copyright $@ 2019$ The Author. This is an open-access article distributed under the terms of the Creative Commons Attribution 4.0 International License (CC-BY).

\section{REFERENCES}

1. Meirinho S, Relvas R, Alves G. Drug-Induced Epistaxis: An Often-Neglected Adverse Effect. Curr Drug Saf 2018;13(2):74-83.

2. Pollice PA, Yoder MG. Epistaxis: a retrospective review of hospitalized patients. Otolaryngol Head Neck Surg 1997;117(1):49-53.

3. Petruson B. Epistaxis. A clinical study with special reference to fibrinolysis. Acto Otolaryngol Supp/ 1974;317:1-73.

4. Schaitkin B, Strauss M, Houck JR. Epistaxis: medical versus surgical therapy: a comparison of efficacy, complications, and economic considerations. Laryngoscope 1987;97(12):1392-1396.

5. Petruson B, Rudin R. The frequency of epistaxis in a male population sample Rhinology 1975;13(3):129-133.

6. Kucik CJ, Clenney T. Management of epistaxis. Am Fam Physician 2005;71(2):305-311.
7. Tan LK, Calhoun KH. Epistaxis. Med Clin North Am 1999;83(1):43-56.

8. Cassisi NJ, Biller HF, Ogura JH. Changes in arterial oxygen tension and pulmonary mechanics with the use of posterior packing in epistaxis: a preliminary report. Laryngoscope 1971;81(8):1261-1266.

9. Lucente FE. Thanatology: a study of 100 deaths. Trans Am Acad Ophthalmol Otolaryngol 1972;76(2):334-339.

10. Pallin DJ, Chng YM, McKay MP, Emond JA, Pelletier AJ, Camargo CA, Jr. Epidemiology of epistaxis in US emergency departments, 1992 to 2001. Ann Emerg Med 2005;46(1):77-81.

11. Alter H. Approach to the adult with epistaxis. In: UpToDate, Grayzel J (Ed), UpToDate, Waltham, MA. Available at: https://www.uptodate.com/contents/approach-to-the-adult-with-epistaxis. Accessed September 18, 2018.

12. Womack JP, Kropa J, Jimenez Stabile M. Epistaxis: Outpatient Management. Am Fam Physician 2018;98(4):240-245.

13. Walker TW, Macfarlane TV, McGarry GW. The epidemiology and chronobiology of epistaxis: an investigation of Scottish hospital admissions 1995-2004. Clin Otolaryngol 2007;32(5):361-365.

14. Brown NJ, Berkowitz RG. Epistaxis in healthy children requiring hospital admission. Int J Pediatr Otorhinolaryngol 2004;68(9):1181-1184.

15. McIntosh N, Mok JY, Margerison A. Epidemiology of oronasal hemorrhage in the first 2 years of life: implications for child protection. Pediatrics 2007;120(5):1074-1078.

16. Seidel DU, Sesterhenn AM, Kostev K. Seasonal Variation of Epistaxis in Germany. J Craniofac Surg 2018;29(4):e365-e367.

17. Tomkinson A, Roblin DG, Flanagan P, Quine SM, Backhouse S. Patterns of hospital attendance with epistaxis. Rhinology 1997;35(3):129-131.

18. Daniell HW. Estrogen prevention of recurrent epistaxis. Arch Otolaryngol Head Neck Surg 1995;121(3):354.

19. Fishpool SJ, Tomkinson A. Patterns of hospital admission with epistaxis for 26,725 patients over an 18-year period in Wales, UK. Ann $R$ Coll Surg Engl 2012;94(8):559-562.

20. Tabassom A, Cho Jj: Epistaxis (Nose Bleed). In: StatPearls. edn. Treasure Island (FL); 2018.

21. Viehweg TL, Roberson JB, Hudson JW. Epistaxis: diagnosis and treatment. J Oral Maxillofac Surg 2006;64(3):511-518.

22. Douglas R, Wormald PJ. Update on epistaxis. Curr Opin Otolaryngol Head Neck Surg 2007;15(3):180-183.

23. Chiu T, Dunn JS. An anatomical study of the arteries of the anterior nasal septum. Otolaryngol Head Neck Surg 2006;134(1):33-36.

24. Viducich RA, Blanda MP, Gerson LW. Posterior epistaxis: clinical features and acute complications. Ann Emerg Med 1995;25(5):592-596.

25. Alvi A, Joyner-Triplett N. Acute epistaxis. How to spot the source and stop the flow. Postgrad Med 1996;99(5):83-90, 94-86.

26. Koh E, Frazzini VI, Kagetsu NJ. Epistaxis: vascular anatomy, origins, and endovascular treatment. AJR Am J Roentgenol 2000;174(3):845-851.

27. Thornton MA, Mahesh BN, Lang J. Posterior epistaxis: identification of common bleeding sites. Laryngoscope 2005;115(4):588-590.

28. Yau S. An update on epistaxis. Aust Fam Physician 2015;44(9):653-656.

29. Mieda M, Miyashita H, Osawa $\mathrm{H}$, et al. Risk factors for nasal bleeding in patients undergoing transnasal gastrointestinal endoscopy. Kaohsiung J Med Sci 2018;34(5):295-300.

30. Morgan DJ, Kellerman R. Epistaxis: evaluation and treatment. Prim Care 2014;41(1):63-73.

31. Kalan A, Tariq M. Foreign bodies in the nasal cavities: a comprehensive review of the aetiology, diagnostic pointers, and therapeutic measures. Postgrad Med J 2000;76(898):484-487.

32. Tong JL, Tung A. A Randomized Trial Comparing the Effect of Fiberoptic Selection and Guidance Versus Random Selection, Blind Insertion, and Direct Laryngoscopy, on the Incidence and Severity of Epistaxis After Nasotracheal Intubation. Anesth Analg 2018;127(2):485-489.

33. Farooq W, Baig SJAoO-H, Surgery N. An Unusual Nasal Mass: The Sinonasal Teratocarcinosarcoma. Archives of Otorhinolaryngology-Head \& Neck Surgery;2(1):1.

34. Kuo CL, Wang MC, Chu CH, Shiao AS. New therapeutic strategy for treating otitis media with effusion in postirradiated nasopharyngeal carcinoma patients. J Chin Med Assoc 2012;75(7):329-334.

35. Makhasana JA, Kulkarni MA, Vaze S, Shroff AS. Juvenile nasopharyngeal angiofibroma. J Oral Maxillofac Pathol 2016;20(2):330.

36. Fatakia A, Winters R, Amedee RG. Epistaxis: a common problem. Ochsner $J$ 2010;10(3):176-178

37. Ferre Aracil C, Nunez Gomez L, Tellez Villajos L, Albillos Martinez A. Epistaxis in the cirrhotic patient: A complication to be considered. Gastroenterol Hepatol 2018. 
38. Wei W, Lai Y, Zang C, et al. A blind area of origins of epistaxis: technical or cog nitive? Eur Arch Otorhinolaryngol 2018;275(6):1501-1505.

39. Lubianca Neto JF, Fuchs FD, Facco SR, et al. Is epistaxis evidence of end-organ damage in patients with hypertension? Laryngoscope 1999;109(7 Pt 1):1111-1115.

40. Melia L, McGarry GW. Epistaxis: update on management. Curr Opin Otolaryngol Head Neck Surg 2011;19(1):30-35.

41. Kikidis D, Tsioufis K, Papanikolaou V, Zerva K, Hantzakos A. Is epistaxis associated with arterial hypertension? A systematic review of the literature. Eur Arch Otorhinolaryngol 2014;271(2):237-243.

42. McGarry GW, Gatehouse S, Hinnie J. Relation between alcohol and nose bleeds. BMJ 1994;309(6955):640.

43. Whitehead KJ, Sautter NB, McWilliams JP, et al. Effect of Topical Intranasal Therapy on Epistaxis Frequency in Patients With Hereditary Hemorrhagic Telangiectasia: A Randomized Clinical Trial. JAMA 2016;316(9):943-951.

44. Donaldson JW, McKeever TM, Hall IP, Hubbard RB, Fogarty AW. The UK prevalence of hereditary haemorrhagic telangiectasia and its association with sex, socioeconomic status and region of residence: a population-based study. Tho$\operatorname{rax} 2014 ; 69(2): 161-167$

45. Middleton PM. Epistaxis. Emerg Med Australas 2004;16(5-6):428-440.

46. Shah RK, Dhingra JK, Shapshay SM. Hereditary hemorrhagic telangiectasia: a review of 76 cases. Laryngoscope 2002;112(5):767-773.

47. Faughnan ME, Palda VA, Garcia-Tsao G, et al. International guidelines for the diagnosis and management of hereditary haemorrhagic telangiectasia. $J$ Med Genet 2011;48(2):73-87.

48. Stokes P, Rimmer J. Intranasal bevacizumab in the treatment of HHT -related epistaxis: a systematic review. Rhinology 2018;56(1):3-10.

49. Hsu YP, Hsu CW, Bai CH, Cheng SW, Chen C. Medical Treatment for Epistaxis in Hereditary Hemorrhagic Telangiectasia: A Meta-analysis. Otolaryngol Head Neck Surg 2018:194599818797316.

50. Halderman AA, Ryan MW, Marple BF, Sindwani R, Reh DD, Poetker DM. Bevacizumab for Epistaxis in Hereditary Hemorrhagic Telangiectasia: An Evidence-based Review. Am J Rhinol Allergy 2018;32(4):258-268.

51. Iyer VN, Apala DR, Pannu BS, et al. Intravenous Bevacizumab for Refractory Hereditary Hemorrhagic Telangiectasia-Related Epistaxis and Gastrointestinal Bleeding. Mayo Clin Proc 2018;93(2):155-166.

52. Invernizzi R, Quaglia F, Klersy C, et al. Efficacy and safety of thalidomide for the treatment of severe recurrent epistaxis in hereditary haemorrhagic telangiectasia: results of a non-randomised, single-centre, phase 2 study. Lancet Haematol 2015;2(11):e465-473.

53. Harrison L, Kundra A, Jervis P. The use of thalidomide therapy for refractory epistaxis in hereditary haemorrhagic telangiectasia: systematic review. J Laryngol Otol 2018:1-6.

54. Drews RE, Leung L, Landaw SJU. Approach to the adult patient with a bleeding diathesis. In: UpToDate, Waltham, MA.

55. Comelli I, Vincenti V, Benatti M, et al. Influence of air temperature variations on incidence of epistaxis. Am J Rhinol Allergy 2015;29(6):e175-181.

56. McGarry GW, Gatehouse S, Vernham G. Idiopathic epistaxis, haemostasis and alcohol. Clin Otolaryngol Allied Sci 1995;20(2):174-177.

57. Danielides V, Kontogiannis N, Bartzokas A, Lolis CJ, Skevas A. The influence of meteorological factors on the frequency of epistaxis. Clin Otolaryngol Allied Sci 2002;27(2):84-88.

58. Nunez DA, McClymont LG, Evans RA. Epistaxis: a study of the relationship with weather. Clin Otolaryngol Allied Sci 1990;15(1):49-51.

59. Okafor BC. Epistaxis: a clinical study of 540 cases. Ear Nose Throat 1984:63(3):153-159.

60. Manfredini R, Gallerani M, Portaluppi F. Seasonal variation in the occurrence of epistaxis. Am J Med 2000;108(9):759-760.

61. Jacobson JA, Kasworm EM. Toxic shock syndrome after nasal surgery. Case reports and analysis of risk factors. Arch Otolaryngol Head Neck Surg 1986;112(3):329-332.

62. Rosenblut A, Bardin PG, Muller B, et al. Long-term safety of fluticasone furoate nasal spray in adults and adolescents with perennial allergic rhinitis. Allergy 2007;62(9):1071-1077.

63. Salib RJ, Howarth PH. Safety and tolerability profiles of intranasal antihistamines and intranasal corticosteroids in the treatment of allergic rhinitis. Drug Saf 2003;26(12):863-893.

64. Waddell AN, Patel SK, Toma AG, Maw AR. Intranasal steroid sprays in the treatment of rhinitis: is one better than another? J Laryngol Otol 2003;117(11):843-845.

65. Benninger MS, Hadley JA, Osguthorpe JD, et al. Techniques of intranasal steroid use. Otolaryngol Head Neck Surg 2004;130(1):5-24.
66. Sastre J, Mosges R. Local and systemic safety of intranasal corticosteroids. J Investig Allergol Clin Immunol 2012;22(1):1-12.

67. Manfredini R, Portaluppi F, Salmi R, Martini A, Gallerani M. Circadian variation in onset of epistaxis: analysis of hospital admissions. BMJ 2000;321(7269):1112.

68. Sauter TC, Hegazy K, Hautz WE, et al. Epistaxis in anticoagulated patients: Fewer hospital admissions and shorter hospital stays on rivaroxaban compared to phenprocoumon. Clin Otolaryngol 2018;43(1):103-108.

69. Hart RG, Pearce LA. In vivo antithrombotic effect of aspirin: dose versus nongastrointestinal bleeding. Stroke 1993;24(1):138-139.

70. Beran $M$, Petruson B. Occurrence of epistaxis in habitual nose-bleeders and analysis of some etiological factors. ORL J Otorhinolaryngol Relat Spec 1986;48(5):297-303

71. Tay HL, Evans JM, McMahon AD, MacDonald TM. Aspirin, nonsteroidal anti-inflammatory drugs, and epistaxis. A regional record linkage case control study. Ann Otol Rhinol Laryngol 1998;107(8):671-674.

72. Stadler RR, Kindler R, Holzmann D, Soyka MB. The long-term fate of epistaxis patients with exposure to antithrombotic medication. Eur Arch Otorhinolaryngol 2016;273(9):2561-2567.

73. Hull RD, Garcia DA. Management of warfarin-associated bleeding or supratherapeutic INR. In: UpToDate, Leung LLK (Ed), UpToDate, Waltham, MA. Available at: https://www.uptodate.com/contents/management-of-warfarin-associated-bleeding-or-supratherapeutic-inr. Accessed September 18, 2018.

74. Buchberger AMS, Baumann A, Johnson F, et al. The role of oral anticoagulants in epistaxis. Eur Arch Otorhinolaryngol 2018;275(8):2035-2043.

75. Veeger NJ, Piersma-Wichers M, Meijer K, Hillege HLJBjoh. Minor bleeds alert for subsequent major bleeding in patients using vitamin $\mathrm{K}$ antagonists. 2011;153(4):508-514.

76. Pond F, Sizeland A. Epistaxis. Strategies for management. Aust Fam Physician 2000;29(10):933-938.

77. Frazee TA, Hauser MS. Nonsurgical management of epistaxis. J Oral Maxillofac Surg 2000;58(4):419-424.

78. Thaha MA, Nilssen EL, Holland S, Love G, White PS. Routine coagulation screening in the management of emergency admission for epistaxis--is it necessary? Laryngol Otol 2000;114(1):38-40.

79. Shakeel M, Trinidade A, Iddamalgoda T, Supriya M, Ah-See KW. Routine clotting screen has no role in the management of epistaxis: reiterating the point. Eur Arch Otorhinolaryngol 2010;267(10):1641-1644.

80. Krempl GA, Noorily AD. Use of oxymetazoline in the management of epistaxis. Ann Otol Rhinol Laryngol 1995;104(9 Pt 1):704-706.

81. Doo G, Johnson DS. Oxymetazoline in the treatment of posterior epistaxis. $\mathrm{Ha}$ waii Med J 1999;58(8):210-212.

82. Bellew SD, Johnson KL, Nichols MD, Kummer T. Effect of Intranasal Vasoconstrictors on Blood Pressure: A Randomized, Double-Blind, Placebo-Controlled Trial. J Emerg Med 2018;55(4):455-464.

83. Bequignon E, Verillaud B, Robard L, et al. Guidelines of the French Society of Otorhinolaryngology (SFORL). First-line treatment of epistaxis in adults. Eur Ann Otorhinolaryngol Head Neck Dis 2017;134(3):185-189.

84. Messner AH. Management of epistaxis in children. In: UpToDate, Stack AM Isaacson GC (Eds), UpToDate, Waltham, MA. Available at: https://www.uptodate.com/contents/management-of-epistaxis-in-children. Accessed September 18, 2018.

85. Stadler RR, Kindler RM, Landis BN, Vogel NI, Holzmann D, Soyka MB. Emergency consultation for epistaxis: A bad predictor for overall health? Auris Nasus Larynx 2018;45(3):482-486

86. Kosugi EM, Balsalobre L, Mangussi-Gomes J, et al. Breaking paradigms in severe epistaxis: the importance of looking for the S-point. Braz J Otorhinolaryngol 2018;84(3):290-297.

87. Pope LE, Hobbs CG. Epistaxis: an update on current management. Postgrad Med J 2005;81(955):309-314.

88. Turri-Zanoni M, Arosio AD, Stamm AC, et al. Septal branches of the anterior ethmoidal artery: anatomical considerations and clinical implications in the management of refractory epistaxis. Eur Arch Otorhinolaryngol 2018;275(6):1449-1456.

89. Badran K, Malik TH, Belloso A, Timms MS. Randomized controlled trial comparing Merocel and RapidRhino packing in the management of anterior epistaxis. Clin Otolaryngol 2005;30(4):333-337.

90. Pringle MB, Beasley P, Brightwell AP. The use of Merocel nasal packs in the treatment of epistaxis. J Laryngol Otol 1996;110(6):543-546.

91. Mathiasen RA, Cruz RM. Prospective, randomized, controlled clinical trial of a novel matrix hemostatic sealant in patients with acute anterior epistaxis. Laryngoscope 2005;115(5):899-902. 


\section{REVIEW}

92. Wang J, Cai C, Wang S. Merocel versus Nasopore for nasal packing: a meta-analysis of randomized controlled trials. PLoS One 2014;9(4):e93959.

93. Schlosser RJ. Clinical practice. Epistaxis. N Engl J Med 2009;360(8):784-789.

94. Schlegel-Wagner C, Siekmann U, Linder T. Non-invasive treatment of intractable posterior epistaxis with hot-water irrigation. Rhinology 2006;44(1):90-93.

95. Novoa E, Schlegel-Wagner C. Hot water irrigation as treatment for intractable posterior epistaxis in an out-patient setting. J Laryngol Otol 2012;126(1):58-60.

96. Seidman MD. Hot-water irrigation in the treatment of posterior epistaxis. Arch Otolaryngol Head Neck Surg 1999;125(11):1285.

97. Stangerup SE, Dommerby H, Lau T. Hot-water irrigation as a treatment of posterior epistaxis. Rhinology 1996;34(1):18-20.

98. Very Hot Compresses in Surgical Practice-Hot Water in Epistaxis. Ind Med Gaz 1889;24(2):49.

99. Perretta LJ, Denslow BL, Brown CG. Emergency evaluation and management of epistaxis. Emerg Med Clin North Am 1987;5(2):265-277.

100. Dubel GJ, Ahn SH, Soares GM. Transcatheter embolization in the management of epistaxis. Semin Intervent Radiol 2013;30(3):249-262.

101. Weddell G, Macbeth RG, et al. The surgical treatment of severe epistaxis in relation to the ethmoidal arteries. Br J Surg 1946;34:387-392.

102. Pritikin JB, Caldarelli DD, Panje WR. Endoscopic ligation of the internal maxillary artery for treatment of intractable posterior epistaxis. Ann Otol Rhinol Laryngol 1998;107(2):85-91.

103. Abdelkader M, Leong SC, White PS. Endoscopic control of the sphenopalatine artery for epistaxis: long-term results. J Laryngol Otol 2007;121(8):759-762.

104. Rejas Ugena E, Trinidad Ruiz G, Alvarez Dominguez J, Carrasco Claver F, Pino Rivero $\mathrm{V}$, Blasco Huelva A. [Utility of the surgical treatment for severe epistaxis by endoscopic approach of sphenopalatine and ethmoidal arteries]. Acta Otorrinolaringol Esp 2006;57(5):228-234.

105. Hull HF, Mann JM, Sands CJ, Gregg SH, Kaufman PW. Toxic shock syndrome related to nasal packing. Arch Otolaryngol 1983;109(9):624-626.

106. Corbridge RJ, Djazaeri B, Hellier WP, Hadley J. A prospective randomized controlled trial comparing the use of merocel nasal tampons and BIPP in the control of acute epistaxis. Clin Otolaryngol Allied Sci 1995;20(4):305-307.

107. Singer AJ, Blanda $M$, Cronin $K$, et al. Comparison of nasal tampons for the treatment of epistaxis in the emergency department: a randomized controlled trial. Ann Emerg Med 2005;45(2):134-139.

108. McGlashan JA, Walsh R, Dauod A, Vowles A, Gleeson MJ. A comparative study of calcium sodium alginate (Kaltostat) and bismuth tribromophenate (Xeroform) packing in the management of epistaxis. J Laryngol Otol 1992;106(12):1067-1071.

109. McFerran DJ, Edmonds SE. The use of balloon catheters in the treatment of epistaxis. J Laryngol Otol 1993;107(3):197-200.

110. Goddard JC, Reiter ER. Inpatient management of epistaxis: outcomes and cost. Otolaryngol Head Neck Surg 2005;132(5):707-712.

111. Biswas D, Mal RK. Are systemic prophylactic antibiotics indicated with anterior nasal packing for spontaneous epistaxis? Acta Otolaryngol 2009;129(2):179-181.

112. Williams M, Onslow J. Airway difficulties associated with severe epistaxis. Anaesthesia 1999;54(8):812-813.

113. Diamond L. Managing epistaxis. JAAPA 2014;27(11):35-39.

114. Kubba $\mathrm{H}$, MacAndie $\mathrm{C}$, Botma $\mathrm{M}$, et al. A prospective, single-blind, randomized controlled trial of antiseptic cream for recurrent epistaxis in childhood. Clin Otolaryngol Allied Sci 2001;26(6):465-468. 